\title{
1 Unusual evolution of tree frog populations in the Chernobyl
}

\section{2 exclusion zone}

3 Clément Car $^{1 *}$, André Gilles ${ }^{2}$, Olivier Armant ${ }^{1}$, Pablo Burraco ${ }^{3,4}$, Karine Beaugelin-Seiller ${ }^{1}$,

4 Sergey Gashchak ${ }^{5}$, Virginie Camilleri ${ }^{1}$, Isabelle Cavalie ${ }^{1}$, Patrick Laloi ${ }^{1}$, Christelle Adam-

5 Guillermin $^{6}$, Germán Orizaola ${ }^{7,8}$ and Jean-Marc Bonzom ${ }^{1 *}$

8

9

10

${ }^{1}$ Institut de Radioprotection et de Sûreté Nucléaire (IRSN), PSE-ENV/SRTE/LECO, Cadarache, 13115, Saint Paul Lez Durance, France

${ }^{2}$ UMR RECOVER, Aix-Marseille Université, INRAE, centre Saint-Charles, 3 place Victor Hugo, 13331 Marseille, France

${ }^{3}$ Animal Ecology, Department of Ecology and Genetics, Evolutionary Biology Centre, Uppsala University, Norbyvägen 18D, SE-75236 Uppsala, Sweden

${ }^{4}$ Institute of Biodiversity, Animal Health and Comparative Medicine, College of Medical, Veterinary and Life Sciences, University of Glasgow, Glasgow G12 8QQ, United Kingdom

${ }^{5}$ Chornobyl Center for Nuclear Safety, Radioactive Waste and Radioecology, 07100, Slavutych, Ukraine

${ }^{6}$ Institut de Radioprotection et de Sûreté Nucléaire (IRSN), PSE-SANTE/SDOS/LMDN, Cadarache, 13115, Saint Paul Lez Durance, France

${ }^{7}$ IMIB-Biodiversity Research Institute (Univ. Oviedo-CSIC-Princip. Asturias), Universidad de Oviedo, Campus de Mieres, Edificio de Investigación 5ª planta, c/ Gonzalo Gutiérrez Quirós s/n, 33600 Mieres-Asturias, Spain

${ }^{8}$ Zoology Unit, Department Biology Organisms and Systems, University of Oviedo, c/ Catedrático Rodrigo Uría s/n, 33071 Oviedo-Asturias, Spain

\section{Abstract}

Despite the ubiquity of pollutants in the environment, their long-term ecological consequences are not always clear and still poorly studied. This is the case concerning the radioactive contamination of the environment following the major nuclear accident at the Chernobyl nuclear power plant. Notwithstanding the implications of evolutionary processes on the population status, few studies concern the evolution of organisms chronically exposed to ionizing radiation in the Chernobyl exclusion zone. Here, we examined genetic markers for 19 populations of Eastern tree frog (Hyla orientalis) sampled in the Chernobyl region about 
thirty years after the nuclear power plant accident to investigate microevolutionary processes ongoing in local populations. Genetic diversity estimated from nuclear and mitochondrial markers showed an absence of genetic erosion and higher mitochondrial diversity in tree frogs from the Chernobyl exclusion zone compared to other European populations. Moreover, the study of haplotype network permitted us to decipher the presence of an independent recent evolutionary history of Chernobyl exclusion zone's Eastern tree frogs caused by an elevated mutation rate compared to other European populations. By fitting to our data a model of haplotype network evolution, we suspected that Eastern tree frog populations in the Chernobyl exclusion zone have a high mitochondrial mutation rate and small effective population sizes. These data suggest that Eastern tree frogs populations might offset the impact of deleterious mutations because of their large clutch size, but also question the long term impact of ionizing radiation on the status of other species living in the Chernobyl exclusion zone. 


\section{Introduction}

The loss of biodiversity during the past 50 years is unprecedented in human history. Pollution, as part of the major drivers of biodiversity loss (namely habitat and climate change, pollution, overexploitation of natural resources, and invasive species), has severely altered many ecosystems ${ }^{1}$. Among the large diversity of pollutants, radioactive contamination caused by human activities, and the associated risks for ecosystems and humans, are the subject of broad societal and scientific concern ${ }^{2}$. This is particularly true in the case of major nuclear accident such as the one occurred at the Chernobyl nuclear power plant (NPP) on April $1986^{3,4}$. Although the short-term adverse effects of high ionizing radiation doses on wildlife following this accident are not questioned ${ }^{5-7}$, there are still many unknowns and controversies on the long-term ecological consequences of these radioactive releases ${ }^{8-11}$.

One of the biggest challenges for an accurate estimation of the impact of chronic pollution on ecosystems, is to understand, quantify and predict its effects not only at individual, but also at population level ${ }^{12-14}$. Understanding the impact of pollutants on populations allows to investigate evolutionary processes that may affect population status and their capacity to persist in the future. Several studies in the Chernobyl area have estimated the abundance and interspecific diversity of wildlife after the accident ${ }^{15-29}$. However, these studies have provided inconclusive, and often divergent results, dependent on the sampling design (e.g. for mammals ${ }^{17,23,30}$ ). In addition, studies investigating the evolution of wildlife in Chernobyl area are scarce, and have not provide solid conclusions ${ }^{31,32}$. In order to increase our understanding on the impact of ionizing radiation on wildlife in the Chernobyl area, we must examine intraspecific genetic variations. Examining genetic variations within and between populations may allow to estimate differences in the intensity of possible evolutionary processes occurring in wildlife populations ${ }^{33-36}$. Evolutionary processes (mutation, migration, genetic drift, selection) must be understood as the mechanisms at the origin of the 
modification of genetic variations within populations. Genetic diversity indices, in particular, can be highly informative from an ecological perspective since changes in genetic diversity can affect the capacity of populations to cope with environmental change ${ }^{37-41}$.

Populations exposed to pollutants often experience genetic erosion ${ }^{35}$. Two processes can be at the origin of this decreased diversity: a directional selective pressure which can be driven by the modification of the environment ${ }^{36,42}$, and/or a demographic bottleneck involving the fixation of polymorphic alleles with neutral $\mathrm{drift}^{38,43-45}$. Most of the population genetic studies carried out in the Chernobyl area have been conducted on the bank vole Myodes glareolus, and showed increased genetic diversity in highly radio-contaminated areas ${ }^{46-51}$. There are two not mutually exclusive explanations for this observation. First, exposure to radioactive

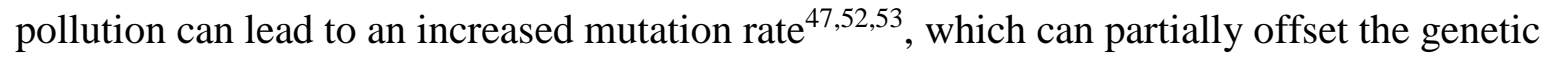
diversity loss caused by population bottlenecks. Alternatively, the Chernobyl exclusion zone (CEZ) - which is an area established soon after the Chernobyl nuclear disaster where human population was evacuated ${ }^{54}$ - could act as an ecological $\operatorname{sink}^{55-58}$ : a demographic deficit caused by the polluted habitat (mortality > natality) could lead to immigration to these habitats, and in fine to an increase in genetic diversity ${ }^{49,59,60}$.

Here, we examine the relationship between radionuclide contamination in the CEZ and the genetic pattern of populations of a lissamphibian species, the Eastern tree frog (Hyla orientalis) ${ }^{61}$ Bedriaga 1890 (Anura, Hylidae). The phylogeography of this species is well understood which allows the examination of Chernobyl populations in the context of the general evolutionary history of the species ${ }^{62}$. In addition, the Eastern tree frog may be significantly exposed to ionizing radiation in both aquatic and terrestrial environments at susceptible stages of its development, especially during the metamorphosis and during its hibernation in the contaminated soil ${ }^{63,64}$. 
We studied population genetics from 19 populations of $H$. orientalis sampled about thirty years after the Chernobyl NPP accident at sites located across a wide range of radioactive contamination inside and outside the CEZ (Fig. 1.b). We used mitochondrial and nuclear genetic markers. These markers differ in their mode of transmission, rate of evolution, and dynamics against environmental disturbances ${ }^{65-67}$. Genetic diversity of populations from the CEZ was compared to that of populations distant up to $40 \mathrm{~km}$ from the CEZ (Slavutych), as well as to five other European populations belonging to the same clade ${ }^{62}$ (Fig. 1a). Finally, we studied the mitochondrial haplotype network and made simulation of networks over 10 and 15 generations in order to estimate the population parameters of frogs living in the CEZ since the accident.

\section{Results}

Mitochondrial DNA heteroplasmies. Based on the analysis of the mitochondrial DNA (mtDNA) of 216 Eastern tree frogs Hyla orientalis sampled in the CEZ and at Slavutych, we observed 20 substitutions composed of 19 transitions (12 C/T and 7 A/G) and 1 transversion (A/T) (Supplementary Tables 1 and 2). By comparing the haplotypes found in the Chernobyl region with the haplogroups described for other areas of Europe ${ }^{61,62}$, we determined that they were part of the clade D4, characteristic of areas from the northern Black Sea shores to the Baltic Sea. In addition, we detected seven individuals from three populations with two different haplotypes in the CEZ which we considered as being cases of heteroplasmy, while none were detected in the other European populations (see Methods, Supplementary Fig. 1 and Supplementary Table 3).

High mitochondrial genetic diversity for CEZ populations. We compared the genetic 
diversity of populations with sufficient sample size ( $\mathrm{n} \geq 7$ individuals) sampled in the CEZ to the populations from Slavutych and to those from other European areas sampled by Dufresnes et al. ${ }^{62}$. Mitochondrial haplotypic and nucleotide diversities of all populations from CEZ $(\mathrm{h}=$ $0.7308, \pi=0.0024)$ were significantly higher $(\mathrm{W}=91, \mathrm{p}<0.005)$ than those of other European populations ( $\mathrm{h}=0.6071, \pi=0.0008)$ (Fig. 2a and Supplementary Table 4). The lowest mitochondrial haplotype diversity was measured for the populations nearest to Chernobyl region, in Kharkiv, Ukraine $(h=0.2500)$ and Luninets, Belarus $(h=0)$ (Figure 1a and Figure 2b). The two Slavutych populations present an intermediate mitochondrial haplotype diversity, as the $\mathrm{H} 18$ population had low genetic diversity $(\mathrm{h}=0.2857)$, while the G18 population had a genetic diversity fairly close to the genetic diversity of the CEZ populations $(h=0.6444)($ Fig. $2 b)$. To compare the variations of mtDNA to nuclear DNA (nDNA) we examined 21 nuclear microsatellites from 126 individuals captured in 2016 and 2017 (Supplementary Table 8). Unlike mtDNA, all the indices of estimated nuclear genetic diversity, such as the genetic diversity within populations (HS) (Fig. 2c), showed no significant differences between the CEZ populations and the other European populations (Supplementary Table 5).

We also investigated the relationship between genetic diversity and the average total dose rates (ATDRs) of ionizing radiation absorbed by individuals in each population of the Chernobyl region (both inside CEZ and around Slavutych; Fig. 1b, see Methods). ATDRs were estimated to provide a more accurate description of the exposure of populations to ionizing radiation than the generally used ambient dose rate, by taking into account the contribution of the different radionuclides and radiation types (alpha, beta and gamma emitters) from all exposure pathways (internal and external) (See Giraudeau et al. ${ }^{63,68}$ as well as Methods and Supplementary note 1). Only mitochondrial nucleotide diversity was significantly positively correlated to ATDRs $(S=294$, rho $=0.640, p=0.007)$ (Fig. 3a and 
Supplementary Table 6). In contrast, the correlation between mitochondrial haplotype diversity and ATDR was not significant $(S=658$, rho $=0.193, p=0.455 ;$ Fig. 3b). Genetic diversity in nuclear microsatellites was not significantly correlated with ATDRs, although these parameters showed a non-significant negative correlation $(S=194$, rho $=-0.617, p=$ 0.086; Fig. 3c). Only private allelic richness and ATDRs were significantly negatively correlated $(\mathrm{S}=221.13$, rho $=-0.843, \mathrm{p}=0.004)$ (Supplementary Table 7).

Local geographical structure of genetic variation. In order to study the genetic structure of populations sampled in the CEZ and the Slavutych area, we used a pairwise genetic differentiation estimator between populations (pairwise Fst) ${ }^{69}$. Unlike the low differentiation estimated with nuclear microsatellites $(-0.031<$ Fst $<0.093)$, differentiation estimated from cytochrome $b$ sequences was relatively high $(-0.173<$ Fst $<0.426)$. The highest genetic differentiations for mitochondrial marker (cytochrome b) were observed between the South West A17 and North D18 populations, and other populations $(0.072<$ Fst $<0.426$, Fig. 4a). Slavutych populations were also highly genetically differentiated from CEZ populations $(0.095<$ Fst < 0.395). Genetic pairwise differentiations estimated on nuclear markers were similar to those estimated on mitochondrial markers, the most differentiated population being A17 (0.021 < Fst < 0.093, Fig. 4b). Despite the absence of a complete similarity between geographical and genetic structures (Figs. $1 \mathrm{~b}$ and $4 \mathrm{a}, \mathrm{b}$ ), the genetically closest populations were, as expected, usually the geographically closest populations. This similarity was obvious when separating populations in Neighbour Joining (NJ) trees build for each sampling year (Supplementary Fig. 2).

We examine the effects of year of sampling, and sampling site on the distribution of mitochondrial genetic structure, using Analysis of Molecular Variance (AMOVA). We used three year groups $(2016,2017,2018)$, and three geographical areas corresponding to three 
groups of populations in the Chernobyl region: one in the North close to the NPP, one on the South of the exclusion zone, and one including the Slavutych populations (Fig. 4c). In both cases, the highest variance was observed within populations ( $83.75 \%$ and $79.85 \%)$. However, the inter-group variance based on years was not significant $(2.00 \%, \mathrm{p}>0.05)$, in opposition to the variance based on geographical regions $(12.27 \%, \mathrm{p}<0.001)$.

In order to test if the increase of genetic distance between populations was shaped by their geographic distances ("isolation by distance" hypothesis), we run Mantel test ${ }^{70}$ between pairwise genetic distances matrix estimated from Fst and pairwise geographic distances matrix. Isolation by distance was significant for both nuclear $(\mathrm{r}=0.4453, \mathrm{p}=0.005)$, and mitochondrial markers $(\mathrm{r}=0.3461, \mathrm{p}=0.009)$. The correspondence between nuclear and mitochondrial genetic distances described from $\mathrm{NJ}$ trees was also significant $(\mathrm{r}=0.6627, \mathrm{p}=$ 0.003). Because of a possible link between geography and radionuclide contamination ${ }^{71}$, we also tested if isolation by distance was carried by the ATDRs using a partial Mantel test. The correlation between genetic distances and geographic distances could not be explained by the differences of ATDRs (mtDNA: $r=0.3474$, sign $=0.007$; $\mathrm{nDNA}: \mathrm{r}=0.4452$, $\operatorname{sign}=0.006$ ). These results indicate that the local genetic structure was mainly influenced by geography, but not by years of sampling or levels of radiation exposure.

\section{Haplotype networks and CEZ independent evolutionary processes. Following the first} quantitative part of our study, we then focused on cytochrome b mitochondrial marker as it allowed us studying qualitatively haplotypes of all populations (i.e. CEZ, Slavutych, and populations outside Chernobyl region sampled by Dufresnes et al. ${ }^{62}$; see Fig. 1a), and examined their genealogical links within a network of haplotypes. This approach is a good way to situate populations within an evolutionary context and explore more subtle evolutionary processes than with diversity indices only ${ }^{56}$. By comparing the haplotype 
network of the Chernobyl populations (CEZ and Slavutych areas) with the haplotypes of populations outside the Chernobyl region, we identified a single haplotype common to all populations, the central haplotype (Fig. 5). Because of the star-like distribution of the haplotype network of populations outside the Chernobyl region (in blue, Fig. 5) with respect to this central haplotype, we considered it as the ancestral haplotype.

We detected a discrepancy between the structure of the CEZ haplotype network and those of all other populations, since the population sampled in Slavutych segregated similarly to populations from other European areas analysed by Dufresnes et al. ${ }^{62}$ : the largest haplotype was the central haplotype, surrounded by many one substitution step rare haplotypes (Fig. 5; green and blue). These populations outside the CEZ are in demographic expansion, as confirmed by the rejection of the equilibrium mutation/drift hypothesis $(\mathrm{D}$ Tajima $=-2.2180$, $\mathrm{p}<0.01 ; \mathrm{Fu}$ and Li D* $=-4.4028, \mathrm{p}=0.002 ; \mathrm{R} 2=0.0289, \mathrm{p}=0.001)$. In contrast, the CEZ populations present a different pattern represented by haplotypes at one and two steps from the central haplotype, shared by many individuals (Fig. 5, in red), and these populations are not in demographic expansion $(\mathrm{D}$ Tajima $=-0.5641, \mathrm{p}=0.332 ; \mathrm{Fu}$ and Li D* $=-1.4653, \mathrm{p}=$ $0.089 ; \mathrm{R} 2=0.0663, \mathrm{p}=0.357)$. These results suggested an independent evolutionary history of the CEZ populations compared to other sampled populations, even in the neighbour population of Slavutych.

Small populations and elevated mutation rate in the CEZ. To decipher the factors shaping the particular pattern of the CEZ haplotype network, we simulated the evolution of its mitochondrial haplotype network using a range of parameters, starting with mitochondrial haplotype diversity of Slavutych populations, corresponding to the G18 or H18 haplotype frequencies (see Methods and Supplementary note 2). Simulations were made for different prior parameters and a set of statistics was chosen to describe the haplotype network at the 
$10^{\text {th }}$ and $15^{\text {th }}$ generation, corresponding to a generation time of three and two years, respectively. During a first simulation part, haplotype networks were simulated based on a fluctuating population size since the accident in the range of uniform distribution U(10005000) and a classical rate of nucleotide substitution in mitochondrial DNA for amphibians of $20.37 \times 10^{-9}$ per nucleotide per generation ${ }^{72}$ (Supplementary Table 12 ). The Principal Component Analysis (PCA) was used to compare simulated and observed statistics, and showed that simulated haplotype networks did not match the observed one, the closest Euclidean distance being 11.13, indicating that the diversity of CEZ populations cannot be obtained with this first set of parameters (Fig. 6a.c and Supplementary Fig. 7).

In a second simulation of haplotype networks we used smaller population sizes (three modalities of uniform distribution: $\mathrm{U}(50,100), \mathrm{U}(100,200)$ and $\mathrm{U}(200,300))$ and high nucleotide substitution rates (six modalities: $0.005,0.01,0.02,0.04,0.06,0.08$ per haplotype per generation in an infinite model site) (Supplementary Table 13). In contrast to the first simulation, PCA displayed a match between the haplotype networks statistics of the simulated and observed data. Indeed, the observed data was in the space of simulated data based on the two first principal components supporting around $90 \%$ of variance (Fig. 6b). Posterior parameters were then estimated using a Ward hierarchical cluster analysis on Euclidean distance selecting the $5^{\text {th }}$ percentile of the simulated descriptive statistics closest to the observed descriptive statistics (Supplementary Fig. 8). The closest distance was 0.52 and the median of descriptive statistics for the 5 percentile closest simulated values presented important similarity with observed values (Supplementary Fig. 9). Considering the posterior parameters estimated, the diversity of CEZ populations and the particular haplotype network (Fig. 6d) for the studied mitochondrial marker can thus be obtained in 15 generations with a small population $\left(\mathrm{N}_{\max }=100\right)$ and a high nucleotide substitution rate of 0.04 per haplotype per generation. 


\section{Discussion}

Several studies have shown that in the CEZ, where all residents have been evacuated, large mammals in particular are reappearing doubtless due to a decrease of human disturbance to wildlife ${ }^{17,19,20,28}$. Conversely, other studies have shown a decrease in the abundance of some species in the CEZ (birds ${ }^{73}$, insects ${ }^{21}$, mammals ${ }^{23}$ ). There is still no consensus about the long term consequences of the Chernobyl NPP accident, and the effects of exposure to ionizing radiation on population status remain mostly unknown. To date very few studies have focused on the evolutionary processes occurring in natural populations that underwent chronic exposure since the 1986 Chernobyl NPP accident. To the best of our knowledge, our study is populations, in comparison to the global European evolution of the closest lineage to which they belong, (ii) using both qualitative and quantitative mitochondrial genetic information and quantitative nuclear genetic information to estimate the best evolutionary scenario responsible of the observed pattern.

A higher mtDNA diversity in the CEZ driven by mutation process. In contrast to the expected genetic erosion induced by wildlife exposure to a pollutant ${ }^{35}$, our results did not show a genetic bottleneck of $H$. orientalis populations in the CEZ compared to the other European populations studied by Dufresnes et al. ${ }^{62}$. We found a higher mitochondrial genetic diversity for the populations in the CEZ, while similar nuclear genetic diversity was observed between CEZ populations and other European populations. These results on mitochondrial diversity agree with the increased mitochondrial genetic diversity observed on bank voles, Myodes glareolus, from the most contaminated areas of the $\mathrm{CEZ}^{47}$. A higher diversity can be explained by two evolutionary processes: migrations from multiple distinct and distant 
mitochondrial markers may orienting towards one of these two mechanisms ${ }^{74,75}$. Indeed repair mechanisms in mtDNA are usually considered less effective than in nDNA ${ }^{76,77}$ notably because of variations in replication mechanism (i.e. low fidelity of the DNA polymerase $\gamma$ ) and a higher number of genome replications per generation especially during oocyte maturation ${ }^{78}$. Thus, the emergence of a mutagenic factor in the environment can induce mutations on mtDNA without increasing nDNA mutations at the same rate. A high migration rate of animals towards the CEZ would increase both mitochondrial and nuclear diversity, a pattern that does not corresponds with our observations. Hence, an increased mutation rate in the CEZ is the most likely explanation to the local genetic novelty and increased genetic diversity for mtDNA and not for nDNA.

A genetic structure consistent with a higher mutation rate in the CEZ. Mitochondrial and nuclear markers differ also in their range of differentiations between populations, but not in the relative structure of these populations. Indeed, based on pairwise Fst values, the most differentiated populations using mtDNA markers are highly differentiated $(>0.4)$, but not when using nDNA $(<0.1)$. The general structure of these populations is quite similar within the CEZ between mitochondrial and nuclear markers (Fig. 4a.b), and for the two type of markers, isolation by distance is not rejected. In amphibians, dispersion is usually male-biased (reviewed by ${ }^{79}$, but see $^{80}$ ). Since mtDNA is transmitted by females, in case of a strong migration process, there would have been a discrepancy between the relative nuclear and mitochondrial population genetic structure. These results, thus, confirm the absence of a strong tree frog migration process coming from outside the CEZ, and reaffirm the role of mutation processes occurring on mtDNA. The presence of mitochondrial haplotypes exclusive to the CEZ - in contrast to previous studies on bank voles ${ }^{81}$ - and the absence in the Chernobyl region of haplotypes shared with populations outside the Chernobyl region (except ancestral haplotype), support also the hypothesis of absence of numerous long migration 
between CEZ and other areas. In this way, the mutation/drift balance explains the higher differentiation found in mtDNA population structure.

Substitution rate and population size at the origin of a "refugia-like" population. The

structure that differs from what can be expected from the global demographic expansion of the clade $\mathrm{D} 4^{61,62}$. This structure is similar to an ancient diversified population, strong mutation rate coupled with populations of small sizes might be responsible for the establishment of the CEZ haplotype network structure. Our haplotype network simulation haplotype per generation of 0.04 and populations of small effective size inferior to 100 individuals (Fig. 6). We noticed a better match between the observed network and the simulated network after 15 generations than after 10 generations. Although $H$. orientalis

strategy. A shorter generation time may be an adaptive response to cope with the accumulation of damage in stressful environments ${ }^{87,88}$, as those with radioactive contamination. mitochondrial evolutionary pattern of the CEZ populations, which seems to be the result of a dynamic comparable to an accelerated evolution, is not observed outside the CEZ. 
Slavutych's tree frog populations that are geographically close to the CEZ populations do not show the same haplotype structure and did not present any case of heteroplasmy, contrary to the CEZ populations. Knowing the mutagenic ability of ionizing radiation ${ }^{89}$, it seems highly likely that the increase of mitochondrial substitution rate by several hundreds of times compared to the mitochondrial substitution rate normally observed in amphibians have been caused by ionizing radiation. Nevertheless, this study does not allow specifying exactly the relationship between the artificial radionuclides exposure and the evolutionary processes estimated from genetic variations. The positive correlation between mitochondrial nucleotide diversity and ATDRs (currently ranging in the frogs samples at the CEZ from 0.007 to 22.4 $\left.\mu \mathrm{Gy} . \mathrm{h}^{-1}\right)$ is in agreement with an effect of ionizing radiation on genetic diversity, but there is no significant correlation between mitochondrial haplotype genetic diversity and ATDRs contrary to the results of Baker et al. on bank voles between haplotype genetic diversity and ambient dose rate ${ }^{47}$. The ATDR seems to be the most relevant dose rate estimator for a population over a time period, but it does not account for exposure of previous generations that occurred since the accident, even though possible transgenerational effects ${ }^{90-92}$ and evolutionary processes should be dependant of these historical doses. The measured mitochondrial substitutions may not only be caused by current exposure to artificial radionuclides, but may be also the result of mutations accumulated by individuals exposed to ionizing radiation in previous generations. There is no information on local tree frog population genetics before the accident and, thus, we cannot exclude uncertainties on the determination of the magnitude of the genetic modifications even if the use of Slavutych populations as a proxy of ancestral populations appears consistent. To fully understand the implication of ionizing radiation on the modification of the intensity of evolutionary processes, it should be valuable to compare these results with similar studies conducted in other radiocontaminated places like the Fukushima prefecture in Japan. 
bioRxiv preprint doi: https://doi.org/10.1101/2020.12.04.412114; this version posted December 6, 2020. The copyright holder for this preprint (which was not certified by peer review) is the author/funder, who has granted bioRxiv a license to display the preprint in perpetuity. It is made available under aCC-BY-NC-ND 4.0 International license.

The key role of mitochondrial DNA in evolutionary ecotoxicology. Our results show that the visible higher genetic diversity may not correspond to a classical evolutionary scenario (i.e. an ancestral population), and that mitochondrial markers are useful to assess the mutagenic effect of ionizing radiation ${ }^{93}$. Previous studies (e.g. Fuller et al. ${ }^{94}$ ) did not find any significant positive correlation between absorbed radiation (ATDRs ranging from 0.064 to $26.4 \mu \mathrm{Gy} \cdot \mathrm{h}^{-1}$ ) and nuclear genetic diversity in the freshwater crustacean Asellus aquaticus from the Chernobyl region. This study concludes that the exposure to ionizing radiation has not significantly influenced genetic diversity in A. aquaticus in the Chernobyl area. The analyses of mitochondrial markers might have provide other complementary information pointing towards a mutation process as showed in our study on $H$. orientalis. Measuring mitochondrial markers is thus important as a tool for estimate the modification of the intensity of evolutionary process, but also because of the probable consequences of mitochondrial mutations on individuals and populations. In humans, mtDNA mutations are responsible of several mitochondrial diseases like optic neuropathy ${ }^{95}$, MELAS $^{96}$ and MERRF syndromes ${ }^{97}$. Because of the possible presence of different mtDNA in a single cell, disease symptoms associated with mtDNA mutation could be generated by quantitative changes in the proportion of mtDNA mutants ${ }^{98}$. Moreover, at the population level, the maternal transmission of mtDNA can prevent selection against mutations, which are deleterious only when expressed in males ${ }^{99}$ and can lead to a decrease in population viability ${ }^{100}$.

The necessity of a large space and time scales. Genetic diversity can be sensible to many environmental parameters ${ }^{50}$ and considering a global phylogeographic context could help to overcome this issue. Examining only CEZ and Slavutych tree frogs populations would have been insufficient to draw reliable conclusions about evolutionary processes. However, by putting local estimations of genetic diversity of tree frogs (i.e. in the Chernobyl region) in a global phylogeographic context for the species, we were able to get a more accurate picture of 
the putative effects of radiocontamination on genetic variations and thus potential evolutionary processes of tree frogs populations in the CEZ. Our simulation data shows the need of a certain duration of exposure to radiation as well as the role of other factors like population size, generation time, and the mutation rate, to obtain a network pattern similar to that observed in the CEZ (Fig. 6d). It is possible that, depending on the life history of the organisms, genetic effects are different and/or not fully visible. Such difference might explain other recent findings showing an absence of visible radiation-induced mitochondrial microevolution $^{101}$.

Conclusions. Our study on the genetics of the Eastern tree frog populations in the CEZ suggests the existence of a strong mutation process on mitochondrial DNA, resulting in an unexpected genetic structure of the CEZ populations comparing to other European populations. One challenge now is to understand the possible consequences of this genotypic effect on population status. Due to the crucial role of mitochondria ${ }^{102}$ it seems unlikely these levels of mutation rate does not result in deleterious effects. The small population size predicted by our simulation may be a consequence of the elimination of non-viable individuals at birth, or due to other deleterious effects of ionizing radiation such as a reduction in breeding success (see e.g. ${ }^{103}$ ) or phenotypic disadvantage of mutations ${ }^{104,105}$. If the effects of these mutations do not fully compromise the maintenance of tree frog populations, it is not necessarily true for other organisms with different life history. With their large clutch sizes (up to 600 eggs per female per year ${ }^{106}$ ) tree frogs seem to be effective for supporting the deleterious effects of mutations, but it might not be the case for organisms with smaller litters for example. More detailed studies on species with different life history parameters are clearly needed to have a full picture of the eco-evolutionary effects of wildlife exposure to radioactive contamination. 
395

396

397

398

399

400

401

402

403

404

405

406

407

408

409

410

411

412

413

414

415

416

417

418

\section{Materials and Methods}

\section{1 - Field work, capture and preparation of the samples}

In May and June 2016, 2017, and 2018 during the breeding season, we collected a total of 216 H. orientalis individuals in 17 populations in wetlands located inside the CEZ and 2 outside the CEZ, i.e in the Slavutych region (Fig. 1b). For simplicity, we use here "population" in the meaning of "population sample". These sites cover a gradient of ambient dose rates, that was measured using a hand-held radiometer (MKS-AT6130, ATOMTEX). The mean ( \pm SD) ambient radiation dose rate varied from 0.044 to $32.4 \mu S v \cdot \mathrm{h}^{-1}$. After capture, individuals were kept in individual boxes with a perforated cover and $2 \mathrm{~cm}$ of water until the next morning when they were euthanized and dissected to sample tibia muscle. Collected tissue was quickly frozen at $-196^{\circ} \mathrm{C}$, transported to IRSN labs in Cadarache (France), and stored at $-80{ }^{\circ} \mathrm{C}$ until DNA extraction. The geographic distances separating each pairwise combination of frog populations were estimated with ArcGIS and a UTM projection.

\section{2 - Population-averaged dose rate calculation}

The approach for population-averaged dose rate reconstruction was based on Giraudeau et al., $2018^{63}$ (See Supplementary note 1 for details). The two main differences compared with the protocol carried out by Giraudeau et al. ${ }^{63}$ are the radionuclides and the scenarios under consideration (Supplementary Fig. 3) because of the characteristics of the CEZ compared to the Fukushima situation. To summarize, soil activities (in Bq. $\mathrm{kg}^{-1}$ ) were extracted following Gashchak at al. ${ }^{107}$ from a spatial database using a geometric mean over a 400 m radius area centred on each population location and using a time correction, and water activities were calculated using soil activities and distribution coefficients estimated for the Glubokoye lake $\mathrm{e}^{108}$. In addition, frog activities (in Bq. $\mathrm{kg}^{-1}$ ) were estimated for each individual in femur bones for ${ }^{90} \mathrm{Sr}$, and in leg muscle for ${ }^{137} \mathrm{Cs}$ in the IRL-SSRI Laboratory (Slavutych, Ukraine), 
and then reconstructed for the total frog knowing the total frog mass and the relative mass of bones $(10 \%)$ and muscles $(69 \%)^{109}$. A Canberra-Packard gamma-spectrometer with a high purity germanium (HPGe) detector (GC 3019) was used for measuring ${ }^{137}$ Cs sample activity concentrations and a Beta-spectrometer EXPRESS-01 was used for measuring ${ }^{90} \mathrm{Sr}$ sample activity concentrations. For a more detailed description of measurement method of activity concentration see Beresford et al., 2020 ${ }^{110}$. Then, dose coefficients (DCs) were calculated based on frog morphometry for internal exposure and four scenarios of external exposure using EDEN software ${ }^{111}$. DCs allow converting radionuclide activity (Bq.kg-1 ${ }^{-1}$ Bq. $\left.\mathrm{L}^{-1}\right)$ into dose rate $\left(\mu \mathrm{Gy} \cdot \mathrm{h}^{-1}\right)$ and are specific for each radionuclide/scenario/organism combination. The total dose rate (in $\mu \mathrm{Gy} \cdot \mathrm{h}^{-1}$ ) was calculated for each frog combining related dose coefficients and activities. Average total dose rates (ATDRs) were then obtained averaging for each population total dose rate of sampled individuals (Supplementary Fig. 4 and 5). Only the activity of ${ }^{90} \mathrm{Sr}$ and ${ }^{137} \mathrm{Cs}$ in frogs was measured, but the potential contribution of other less abundant radionuclides $\left({ }^{241} \mathrm{Am},{ }^{238} \mathrm{Pu},{ }^{239} \mathrm{Pu}\right)$ to the total dose rate was estimated, leading to confirm their minor contribution to the total dose rate (on average less than a quarter of the total dose rate; see Supplementary Table 9, 10, 11 and Fig. 6). The total dose rate we assessed could potentially be slightly underestimated as other radionuclides than ${ }^{137} \mathrm{Cs}$ and ${ }^{90} \mathrm{Sr}$ were not included in the dose reconstruction. Nevertheless, in the CEZ the soil activity of ${ }^{90} \mathrm{Sr}$ and ${ }^{137} \mathrm{Cs}$ is correlated to the activity of other less abundant radionuclides ${ }^{68}$ as for the body activity of organisms such as small mammals ${ }^{112}$, thus our ATDR descriptor based on ${ }^{90} \mathrm{Sr}$ and ${ }^{137} \mathrm{Cs}$ is reliable for statistical tests.

\section{3 - DNA extraction, sequencing and genotyping}

DNA was extracted from tibia muscle using DNeasy Blood and Tissue Kit (Qiagen, Valencia, CA) following the manufacturer's protocol. After the estimation of nucleotide concentration with a spectrophotometric measurement and an electrophoresis quality check, a $957 \mathrm{bp}$ 
fragment of mitochondrial DNA, cytochrome b, and 21 nuclear microsatellites were studied (Supplementary Table 8). Mitochondrial and nuclear markers were used simultaneously in order to compare their different properties. To sequence the cytochrome b, a PCR amplification was performed using Hyla-L0 and Hyla-H1046 primers ${ }^{62,113}$. For each amplification session, a negative control was made using $3 \mu \mathrm{L}$ of water instead of extracted DNA, and an electrophoresis was done to control the proper functioning of the amplification. PCR-products were sequenced in both directions using Sanger sequencing (Eurofins, sequencing platform Cochin, France). The quality was checked using ab1 files. Sequences were aligned with MUSCLE program and corrected with MEGA ${ }^{114}$. In some cases, for the same position, an individual showed two different nucleotides. The mtDNA being haploid, it can be interpreted as an heteroplasmy ${ }^{115}$ (i.e. the presence of multiple mtDNA haplotypes in an individual). For each of these individuals, the two haplotypes were considered. Four multiplex amplifications were then performed for the 21 microsatellite markers (Supplementary Table 8). Formamide and a Size Standard were added to the PCR-products and the whole was then genotyped with ABI-3100 Genetic Analyser (ThermoFisher Scientific). A second amplification and genotyping was carried out on 4 individuals in order to check the replicability of the method.

\section{4 - Genetic analyses, mtDNA and nDNA}

First of all, a quantitative analysis of population genetics was performed for the two types of markers. In order to avoid sample size artefacts, only populations with sample size higher or equal than 7 individuals were used to describe the genetic diversity. Because sample sizes were still non-homogeneous between populations, rarefaction technique was performed for cytochrome $\mathrm{b}$ to calculate haplotypic richness $(\mathrm{nrH})$ and private estimated haplotype number (npH) using hp-rare ${ }^{116}$. The haplotype diversity $(h)^{117}$, nucleotide diversity $(\pi)^{118}$ and three estimators of $\theta$ index $(\theta \mathrm{s}, \theta \mathrm{k}, \theta \pi)^{118-120}$ were calculated for the cytochrome b using 
ARLEQUIN $^{121}$. To describe how the mitochondrial genetic variation is structured temporally and geographically, the Analysis of Molecular Variance (AMOVA) ${ }^{69}$ and the calculation of a differentiation index - pairwise Fst - were performed using ARLEQUIN. For microsatellites markers, we estimated the observed heterozygoty (Ho), the estimated heterozygoty under Hardy-Weinberg assumptions (He), the genetic diversity (Hs), the allelic richness (AR) and the private allelic richness (PA) using GENETIX ${ }^{122}$, ADZE $^{123}$, and Fstat ${ }^{124}$. Pairwise Fst for microsatellites were calculated using Fstat. The absolute value of the lowest Fst for the mitochondrial and nuclear markers was added to every pairwise Fst in order to get only positive pairwise Fst. We calculated the ratio Fst/(1-Fst) in order to estimate genetic distance between populations, and represented these distances using Neighbour-Joining trees with genetic distances estimated with MEGA ${ }^{114}$.

A qualitative analysis of sequences was carried out for cytochrome b. The haplotypes were determined using DNAsp ${ }^{125}$, the haplotype network was calculated with the Median-Joining method $^{126}$ and drawn using POPART ${ }^{127}$.

\section{5 - Simulation of haplotype networks}

Simulations of mitochondrial haplotype networks were conducted with a method close to the Approximate Bayesian Computation ${ }^{128}$ (for details on protocol see Supplementary note 2). Simulations of the haplotype evolution during 10 and 15 generations (assuming one generation respectively every two or three years ${ }^{85,86}$ ) in a unique population were conducted in $\mathrm{R}$ and Pegas library ${ }^{129}$ using different parameters: (i) the funder population size $\left(\mathrm{N}_{0}\right)$ corresponding to specimens able to reproduce after the accident, (ii) the frequencies of haplotypes in the founder population based on the current diversity observed for the Slavutych populations, (iii) the population size for each year during the 10 or 15 generations $\left(\mathrm{N}_{1-\mathrm{n}}\right)$, (iv) the nucleotide substitution rate $(\mu)$ and $(\mathrm{v})$ the number of generations. A haplotype 
network was generated for the last generation for each data set obtained with a set of value for prior parameters. After a first simulation running with classical wild frog population prior parameters $^{72}$ (1000 simulations for each modality combination, a total of 6000 simulations), a second simulation was performed with different prior parameters calibrated from the first simulation results (100 simulations for each modality combination, a total of 21600 simulations) (see Supplementary Table 12 and 13 for prior parameters details). Each haplotype network was described by five statistics: the nucleotide diversity $(\pi)$, the D Tajima, the haplotype richness ( $\mathrm{nrH})$, the haplotype diversity (h), and the number of steps separating the ancestral haplotype to the most distant haplotype plus one. A Principal Component Analysis (PCA) was performed to compare simulated and observed descriptive statistics. The two first principal component axes were used to visualise both sets of descriptive statistics. A Ward hierarchical cluster analysis on Euclidean distance was used to select the $5^{\text {th }}$ percentile of the simulated descriptive statistics closest to the observed descriptive statistics. The mean and median of the $5^{\text {th }}$ percentile simulated descriptive statistics were calculated to estimate the posterior parameters $\mathrm{N}_{0}$, the appropriate haplotype frequencies for the founder population, $\mathrm{N}_{1}$. $\mathrm{n}$ and $\mu$. Visualisation of the haplotype network for prior, $10_{\text {th }}$ and $15_{\text {th }}$ generation was done using TempNet ${ }^{130}$.

\section{6 - Statistical analysis}

Non-parametric Wilcoxon signed rank tests were performed to compare genetic diversity indices, between CEZ populations and outside CEZ populations, because of their non-normal distribution tested using Shapiro-Wilk test. Non-parametric Spearman rank test were used to test the correlation between genetic diversity indices and the population-averaged dose rate (ATDR). The correlation between two matrices, the genetic distance matrix obtained with the Fst linearization and the matrix of logarithm of geographical distance (in m), was performed using a Mantel test ${ }^{70}$ with the vegan package ${ }^{131}$. The part of pairwise population-averaged 
518 dose-rate differences between populations on the distances correlation was tested using a

519 partial Mantel test. The significance of Mantel tests was estimated with 9999 permutations.

$520 \quad$ All these tests were carried out on R version 3.6.1. ${ }^{132}$.

521 To test the demographical expansion hypothesis with haplotype networks, three statistical

522 tests were performed on DNAsp. The neutral assumption of the absence of deviation from the

523 mutation-drift equilibrium was tested using the Tajima's $\mathrm{D}^{133}$ and Fu's $\mathrm{D}^{* 134}$. The distribution

524 of pairwise differences between sequences was studied too, using the R2 statistic ${ }^{135}$. 


\section{References}

1. Brondizio, E. S., Settele, J., Díaz, S. \& Ngo, H. T. Global assessment report on biodiversity and ecosystem services of the Intergovernmental Science-Policy Platform on Biodiversity and Ecosystem Services. (2019).

2. Beresford, N. A. \& Copplestone, D. Effects of ionizing radiation on wildlife: What knowledge have we gained between the Chernobyl and Fukushima accidents? Integrated Environ. Assess. Manag. 7, 371-373 (2011).

3. Steinhauser, G., Brandl, A. \& Johnson, T. E. Comparison of the Chernobyl and Fukushima nuclear accidents: A review of the environmental impacts. Sci. Total Environ. 470-471, 800-817 (2014).

4. Imanaka, T., Hayashi, G. \& Endo, S. Comparison of the accident process, radioactivity release and ground contamination between Chernobyl and Fukushima-1. J. Radiat. Res. 56, 56-61 (2015).

5. Geras'kin, S. A., Fesenko, S. V. \& Alexakhin, R. M. Effects of non-human species irradiation after the Chernobyl NPP accident. Environ. Int. 34, 880-897 (2008).

6. Møller, A. P. \& Mousseau, T. A. Biological consequences of Chernobyl: 20 years on. Trends Ecol. Evol. 21, 200-207 (2006).

7. Alexakhin, R. et al. Environmental consequences of the Chernobyl accident and their remediation: Twenty years of experience. Report of the Chernobyl Forum Expert group “Environment”. (International Atomic Energy Agency, 2006).

8. Beresford, N. A. et al. Towards solving a scientific controversy - The effects of ionising radiation on the environment. J. Environ. Radioact. 211, 106033 (2020).

9. Bréchignac, F. \& Paquet, F. Radiation-induced risks at low dose: moving beyond controversy towards a new vision. Radiat. Environ. Bioph. 52, 299-301 (2013). 
10. Mothersill, C. \& Seymour, C. Uncomfortable issues in radiation protection posed by lowdose radiobiology. Radiat. Environ. Bioph. 52, 293-298 (2013).

11. Morgan, W. F. \& Bair, W. J. Issues in low dose radiation biology: the controversy continues. A perspective. Radiat. Res. 179, 501-510 (2013).

12. Bickham, J. W. The four cornerstones of Evolutionary Toxicology. Ecotoxicology 20, 497-502 (2011).

13. Medina, M. H., Correa, J. A. \& Barata, C. Micro-evolution due to pollution: Possible consequences for ecosystem responses to toxic stress. Chemosphere 67, 2105-2114 (2007).

14. Theodorakis, C. W. Integration of genotoxic and population genetic endpoints in biomonitoring and risk assessment. Ecotoxicology 10, 245-256 (2001).

15. Bezrukov, V. et al. Heterogeneous relationships between abundance of soil surface invertebrates and radiation from Chernobyl. Ecol. Indic. 52, 128-133 (2015).

16. Chapon, V. et al. Microbial diversity in contaminated soils along the T22 trench of the Chernobyl experimental platform. J. App. Geochem. 27, 1375-1383 (2012).

17. Deryabina, T. G. et al. Long-term census data reveal abundant wildlife populations at Chernobyl. Curr. Biol. 25, R824-R826 (2015).

18. Lecomte-Pradines, C. et al. Soil nematode assemblages as bioindicators of radiation impact in the Chernobyl Exclusion Zone. Sci. Total Environ. 490, 161-170 (2014).

19. Gashchak, S., Gulyaichenko, Y., Beresford, N. A. \& Wood, M. D. European bison (Bison bonasus) in the Chornobyl Exclusion Zone (Ukraine) and prospects for its revival. Proceedings of the Theriological School 15, 58-66 (2017).

20. Gashchak, S., Gulyaichenko, Y., Beresford, N. A. \& Wood, M. D. Brown bear (Ursus $\operatorname{arctos}$ L.) in the Chornobyl exclusion zone. Proceedings of the Theriological School 14, 71-84 (2016). 
21. Møller, A. P. \& Mousseau, T. A. Reduced abundance of insects and spiders linked to radiation at Chernobyl 20 years after the accident. Biol. Lett. 5, 356-359 (2009).

22. Møller, A. P., Nishiumi, I., Suzuki, H., Ueda, K. \& Mousseau, T. A. Differences in effects of radiation on abundance of animals in Fukushima and Chernobyl. Ecol. Indic. 24, 75-81 (2013).

23. Møller, A. P. \& Mousseau, T. A. Assessing effects of radiation on abundance of mammals and predator-prey interactions in Chernobyl using tracks in the snow. Ecol. Indic. 26, 112-116 (2013).

24. Møller, A. P. \& Mousseau, T. A. Reduced colonization by soil invertebrates to irradiated decomposing wood in Chernobyl. Sci. Total Environ. 645, 773-779 (2018).

25. Morelli, F., Benedetti, Y., Mousseau, T. A. \& Møller, A. P. Ionizing radiation and taxonomic, functional and evolutionary diversity of bird communities. J. Environ. Manage. 220, 183-190 (2018).

26. Murphy, J. F., Nagorskaya, L. L. \& Smith, J. T. Abundance and diversity of aquatic macroinvertebrate communities in lakes exposed to Chernobyl-derived ionising radiation. J. Environ. Radioact. 102, 688-694 (2011).

27. Schlichting, P. E., Love, C. N., Webster, S. C. \& Beasley, J. C. Efficiency and composition of vertebrate scavengers at the land-water interface in the Chernobyl Exclusion Zone. Food Webs 18, e00107 (2019).

28. Shkvyria, M. \& Vishnevskiy, D. Large carnivores of the Chernobyl Nuclear Power Plant Exclusion Zone. Vestnik zoologii 46, 21-28 (2012).

29. Zaitsev, A. S., Gongalsky, K. B., Nakamori, T. \& Kaneko, N. Ionizing radiation effects on soil biota: Application of lessons learned from Chernobyl accident for radioecological monitoring. Pedobiologia 57, 5-14 (2014). 
598

599

600

601

602

603

604

605

606

607

608

609

610

611

612

613

614

615

616

617

618

619

620

621

30. Webster, S. C. et al. Where the wild things are: influence of radiation on the distribution of four mammalian species within the Chernobyl Exclusion Zone. Front. Ecol. Environ. 14, 185-190 (2016).

31. Arnaise, S., Shykoff, J. A., Møller, A. P., Mousseau, T. A. \& Giraud, T. Anther-smut fungi from more contaminated sites in Chernobyl show lower infection ability and lower viability following experimental irradiation. Ecol. Evol. doi:10.1002/ece3.6376.

32. Møller, A. P. \& Mousseau, T. A. Are organisms adapting to ionizing radiation at Chernobyl? Trends Ecol. Evol. 31, 281-289 (2016).

33. Bickham, J. W., Sandhu, S., Hebert, P. D. N., Chikhi, L. \& Athwal, R. Effects of chemical contaminants on genetic diversity in natural populations: implications for biomonitoring and ecotoxicology. Mutat. Res. Rev. Mutat. Res. 463, 33-51 (2000).

34. Giska, I., Babik, W., van Gestel, C. A. M., van Straalen, N. M. \& Laskowski, R. Genomewide genetic diversity of rove beetle populations along a metal pollution gradient. Ecotoxicol. Environ. Saf. 119, 98-105 (2015).

35. Straalen, N. M. van \& Timmermans, M. J. T. N. Genetic variation in toxicant-stressed populations: An evaluation of the "genetic erosion" hypothesis. Hum. Ecol. Risk Assess. 8, 983-1002 (2002).

36. Ungherese, G. et al. Relationship between heavy metals pollution and genetic diversity in Mediterranean populations of the sandhopper Talitrus saltator (Montagu) (Crustacea, Amphipoda). Environ. Pollut. 158, 1638-1643 (2010).

37. Fasola, E., Ribeiro, R. \& Lopes, I. Microevolution due to pollution in amphibians: A review on the genetic erosion hypothesis. Environ. Pollut. 204, 181-190 (2015).

38. Hughes, A. R., Inouye, B. D., Johnson, M. T. J., Underwood, N. \& Vellend, M. Ecological consequences of genetic diversity. Ecol. Lett. 11, 609-623 (2008). 
39. Luquet, E. et al. Consequences of genetic erosion on fitness and phenotypic plasticity in European tree frog populations (Hyla arborea). J. Evol. Biol. 24, 99-110 (2011).

40. Millette, K. L. et al. No consistent effects of humans on animal genetic diversity worldwide. Ecol. Lett. 23, 55-67 (2019).

41. Ribeiro, R. \& Lopes, I. Contaminant driven genetic erosion and associated hypotheses on alleles loss, reduced population growth rate and increased susceptibility to future stressors: an essay. Ecotoxicology 22, 889-899 (2013).

42. De Wolf, H., Blust, R. \& Backeljau, T. The population genetic structure of Littorina littorea (Mollusca: Gastropoda) along a pollution gradient in the Scheldt estuary (The Netherlands) using RAPD analysis. Sci. Total Environ. 325, 59-69 (2004).

43. Murdoch, M. H. \& Hebert, P. D. N. Mitochondrial dna diversity of brown bullhead from contaminated and relatively pristine sites in the great lakes. Environ. Toxicol. Chem. 13, 1281-1289 (1994).

44. Ribeiro, R., Baird, D. J., Soares, A. M. V. M. \& Lopes, I. Contaminant driven genetic erosion: A case study with Daphnia longispina. Environ. Toxicol. Chem. 31, 977-982 (2012).

45. Wang, W., Zheng, Y., Zhao, J. \& Yao, M. Low genetic diversity in a critically endangered primate: shallow evolutionary history or recent population bottleneck? BMC Evol. Biol. 19, 134 (2019).

46. Baker, R. J. et al. Consequences of polluted environments on population structure: The bank vole (Clethrionomys glareolus) at Chornobyl. Ecotoxicology 10, 211-216 (2001).

47. Baker, R. J. et al. Elevated mitochondrial genome variation after 50 generations of radiation exposure in a wild rodent. Evol. Appl. 10, 784-791 (2017). 
48. Matson, C. W., Rodgers, B. E., Chesser, R. K. \& Baker, R. J. Genetic diversity of Clethrionomys glareolus populations from highly contaminated sites in the Chornobyl region, Ukraine. Environ. Toxicol. Chem. 19, 2130-2135 (2000).

49. Meeks, H. N. et al. Mitochondrial control region variation in bank voles (Clethrionomys glareolus) is not related to Chernobyl radiation exposure. Environ. Toxicol. Chem. 26, 361-369 (2007).

50. Meeks, H. N., Chesser, R. K., Rodgers, B. E., Gaschak, S. \& Baker, R. J. Understanding the genetic consequences of environmental toxicant exposure: Chernobyl as a model system. Environ. Toxicol. Chem. 28, 1982-1994 (2009).

51. Wickliffe, J. K. et al. Variation in mitochondrial DNA control region haplotypes in populations of the bank vole, Clethrionomys glareolus, living in the Chernobyl environment, Ukraine. Environ. Toxicol. Chem. 25, 503-508 (2006).

52. Dubrova, Y. E. Long-term genetic effects of radiation exposure. Mutat. Res. Rev. Mutat. Res. 544, 433-439 (2003).

53. Ellegren, H., Lindgren, G., Primmer, C. R. \& Møller, A. P. Fitness loss and germline mutations in barn swallows breeding in Chernobyl. Nature 389, 593-596 (1997).

54. Bondarkov, M. D. et al. Environmental radiation monitoring in the Chernobyl exclusion zone - history and results 25 years after. Health Phys. 101, 442-485 (2011).

55. Dias, P. C. Sources and sinks in population biology. Trends Ecol. Evol. 11, 326-330 (1996).

56. Matson, C. W. et al. Evolutionary Toxicology: Population-level effects of chronic contaminant exposure on the marsh frogs (Rana ridibunda) of Azerbaijan. Environ. Health Perspect. 114, 547-552 (2006).

57. Pulliam, H. R. Sources, sinks, and population regulation. Am. Nat. 132, 652-661 (1988). 
58. Theodorakis, C. W., Bickham, J. W., Lamb, T., Medica, P. A. \& Lyne, T. B. Integration of genotoxicity and population genetic analyses in kangaroo rats (Dipodomys merriami) exposed to radionuclide contamination at the Nevada Test Site, USA. Environ. Toxicol. Chem. 20, 10 (2001).

59. Kesäniemi, J. et al. Analysis of heteroplasmy in bank voles inhabiting the Chernobyl exclusion zone: A commentary on Baker et al. (2017) "Elevated mitochondrial genome variation after 50 generations of radiation exposure in a wild rodent." Evol. Appl. 11, $820-826$ (2018).

60. Møller, A. P., Hobson, K. A., Mousseau, T. A. \& Peklo, A. M. Chernobyl as a population sink for barn swallows: tracking dispersal using stable-isotope profiles. Ecol. Appl. 16, 1696-1705 (2006).

61. Stöck, M. et al. Cryptic diversity among Western Palearctic tree frogs: Postglacial range expansion, range limits, and secondary contacts of three European tree frog lineages (Hyla arborea group). Mol. Phylogenet. Evol. 65, 1-9 (2012).

62. Dufresnes, C. et al. Evolutionary melting pots: a biodiversity hotspot shaped by ring diversifications around the Black Sea in the Eastern tree frog (Hyla orientalis). Mol. Ecol. 25, 4285-4300 (2016).

63. Giraudeau, M. et al. Carotenoid distribution in wild Japanese tree frogs (Hyla japonica) exposed to ionizing radiation in Fukushima. Sci. Rep. 8, 7438 (2018).

64. Stark, K., Scott, D. E., Tsyusko, O., Coughlin, D. P. \& Hinton, T. G. Multi-level effects of low dose rate ionizing radiation on southern toad, Anaxyrus [Bufo] terrestris. PLoS One 10, e0125327 (2015).

65. Brown, W. M., George, M. \& Wilson, A. C. Rapid evolution of animal mitochondrial DNA. PNAS 76, 1967-1971 (1979). 
693

694

695

696

697

698

699

700

701

702

703

704

705

706

707

708

709

710

711

712

713

714

715

716

66. Harrison, R. G. Animal mitochondrial DNA as a genetic marker in population and evolutionary biology. Trends Ecol. Evol. 4, 6-11 (1989).

67. Selkoe, K. \& Toonen, R. Microsatellites for ecologists: A practical guide to using and evaluating microsatellite markers. Ecol. Lett. 9, 615-29 (2006).

68. Bonzom, J.-M. et al. Effects of radionuclide contamination on leaf litter decomposition in the Chernobyl exclusion zone. Sci. Total Environ. 562, 596-603 (2016).

69. Excoffier, L. Analysis of Population Subdivision. in Handbook of Statistical Genetics (American Cancer Society, 2004).

70. Mantel, N. The detection of disease clustering and a generalized regression approach. Cancer Res. 27, 209-220 (1967).

71. Kashparov, V. et al. Spatial datasets of radionuclide contamination in the Ukrainian Chernobyl Exclusion Zone. Earth Syst. Sci. Data 10, 339-353 (2018).

72. Lynch, M. \& Walsh, B. The origins of genome architecture. (Sinauer Associates, 2007).

73. Møller, A. P. \& Mousseau, T. A. Species richness and abundance of forest birds in relation to radiation at Chernobyl. Biol. Lett. 3, 483-486 (2007).

74. Canestrelli, D., Verardi, A. \& Nascetti, G. Genetic differentiation and history of populations of the Italian treefrog Hyla intermedia: lack of concordance between mitochondrial and nuclear markers. Genetica 130, 241 (2006).

75. Toews, D. \& Brelsford, A. The biogeography of mitochondrial and nuclear discordance in animals. Mol. Ecol. 21, 3907-3930 (2012).

76. Kazak, L., Reyes, A. \& Holt, I. J. Minimizing the damage: repair pathways keep mitochondrial DNA intact. Nat. Rev. Mol. Cell Biol. 13, 659-671 (2012).

77. Larsen, N. B., Rasmussen, M. \& Rasmussen, L. J. Nuclear and mitochondrial DNA repair: similar pathways? Mitochondrion 5, 89-108 (2005). 
78. Allio, R., Donega, S., Galtier, N. \& Nabholz, B. Large variation in the ratio of mitochondrial to nuclear mutation rate across animals: Implications for genetic diversity and the use of mitochondrial DNA as a molecular marker. Mol. Biol. Evol. 34, 2762-2772 (2017).

79. Helfer, V., Broquet, T. \& Fumagalli, L. Sex-specific estimates of dispersal show female philopatry and male dispersal in a promiscuous amphibian, the alpine salamander (Salamandra atra). Mol. Ecol. 21, 4706-4720 (2012).

80. Honeycutt, R. K., Garwood, J. M., Lowe, W. H. \& Hossack, B. R. Spatial capturerecapture reveals age- and sex-specific survival and movement in stream amphibians. Oecologia 190, 821-833 (2019).

81. Wickliffe, J. K., Chesser, R. K., Rodgers, B. E. \& Baker, R. J. Assessing the genotoxicity of chronic environmental irradiation by using mitochondrial dna heteroplasmy in the bank vole (Clethrionomys glareolus) at Chornobyl, Ukraine. Environ. Toxicol. Chem. 21, 1249-1254 (2002).

82. Batalha-Filho, H., Cabanne, G. S. \& Miyaki, C. Y. Phylogeography of an Atlantic forest passerine reveals demographic stability through the last glacial maximum. Mol. Phylogenet. Evol. 65, 892-902 (2012).

83. Pulido-Santacruz, P., Bornschein, M. R., Belmonte-Lopes, R. \& Bonatto, S. L. Multiple evolutionary units and demographic stability during the last glacial maximum in the Scytalopus speluncae complex (Aves: Rhinocryptidae). Mol. Phylogenet. Evol. 102, 8696 (2016).

84. Vojtovich, M. A. Bones tumours of Rana temporaria L. in conditions of radionuclide contamination of biotope. Doklady Natsional'noj Akademii Nauk Belarusi 45, 91-94 (2001). 
85. Altunisik, A. \& Özdemir, N. Body size and age structure of a highland population of Hyla orientalis BEDRIAGA, 1890, in northern Turkey. Herpetozoa 26, 49-55 (2013).

86. Özdemir, N. et al. Variation in body size and age structure among three Turkish populations of the treefrog Hyla arborea. Amphibia-Reptilia 33, 25-35 (2012).

87. Dutilleul, M. et al. Adaptation costs to constant and alternating polluted environments. Evol. Appl. 10, 839-851 (2017).

88. Brans, K. I. \& Meester, L. D. City life on fast lanes: Urbanization induces an evolutionary shift towards a faster lifestyle in the water flea Daphnia. Funct. Ecol. 32, 2225-2240 (2018).

89. Breimer, L. H. Ionizing radiation-induced mutagenesis. Br. J. Cancer 57, 6-18 (1988).

90. Hancock, S. et al. Effects of historic radiation dose on the frequency of sex-linked recessive lethals in Drosophila populations following the Chernobyl nuclear accident. Environ. Res. 172, 333-337 (2019).

91. Hancock, S. et al. Transgenerational effects of historic radiation dose in pale grass blue butterflies around Fukushima following the Fukushima Dai-ichi Nuclear Power Plant meltdown accident. Environ. Res. 168, 230-240 (2019).

92. Sakauchi, K., Taira, W., Hiyama, A., Imanaka, T. \& Otaki, J. M. The pale grass blue butterfly in ex-evacuation zones 5.5 years after the Fukushima nuclear accident: Contributions of initial high-dose exposure to transgenerational effects. J. Asia Pac. Entomol. 23, 242-252 (2020).

93. Kam, W. W.-Y. \& Banati, R. B. Effects of ionizing radiation on mitochondria. Free Radical Bio. Med. 65, 607-619 (2013).

94. Fuller, N. et al. Chronic radiation exposure at Chernobyl shows no effect on genetic diversity in the freshwater crustacean, Asellus aquaticus thirty years on. Ecol. Evol. 9, 10135-10144 (2019). 
95. Johns, D. R. \& Neufeld, M. J. Cytochrome b mutations in Leber hereditary optic neuropathy. Biochem. Biophys. Res. Commun. 181, 1358-1364 (1991).

96. Hirano, M. \& Pavlakis, S. G. Topical Review: Mitochondrial Myopathy, Encephalopathy, Lactic Acidosis, and Strokelike Episodes (MELAS): Current Concepts: J. Child Neurol. 9, (1994).

97. Shoffner, J. M. et al. Myoclonic epilepsy and ragged-red fiber disease (MERRF) is associated with a mitochondrial DNA tRNALys mutation. Cell 61, 931-937 (1990).

98. Picard, M. et al. Progressive increase in mtDNA 3243A $>$ G heteroplasmy causes abrupt transcriptional reprogramming. PNAS 111, E4033-E4042 (2014).

99. Innocenti, P., Morrow, E. H. \& Dowling, D. K. Experimental Evidence Supports a SexSpecific Selective Sieve in Mitochondrial Genome Evolution. Science 332, 845-848 (2011).

100. Gemmell, N. J. \& Allendorf, F. W. Mitochondrial mutations may decrease population viability. Trends Ecol. Evol. 16, 115-117 (2001).

101. Newbold, L. K. et al. Genetic, epigenetic and microbiome characterisation of an earthworm species (Octolasion lacteum) along a radiation exposure gradient at Chernobyl. Environ. Pollut. 255, 113238 (2019).

102. Roubicek, D. A. \& Souza-Pinto, N. C. de. Mitochondria and mitochondrial DNA as relevant targets for environmental contaminants. Toxicology 391, 100-108 (2017).

103. Mappes, T. et al. Ecological mechanisms can modify radiation effects in a key forest mammal of Chernobyl. Ecosphere 10, e02667 (2019).

104. Dowling, D. K. Evolutionary perspectives on the links between mitochondrial genotype and disease phenotype. Biochim. Biophys. Acta 1840, 1393-1403 (2014).

105. Ballard, J. W. O. \& Pichaud, N. Mitochondrial DNA: more than an evolutionary bystander. Funct. Ecol. 28, 218-231 (2014). 
106. Broquet, T., Jaquiéry, J. \& Perrin, N. Opportunity for Sexual Selection and Effective Population Size in the Lek-Breeding European Treefrog (Hyla arborea). Evolution 63, 674-683 (2009).

794

107. Gashchak, S., Beresford, N. A., Maksimenko, A. \& Vlaschenko, A. S. Strontium-90 and caesium-137 activity concentrations in bats in the Chernobyl exclusion zone. Radiat. Environ. Bioph. 49, 635-644 (2010).

108. Matsunaga, T. et al. Characteristics of Chernobyl-derived radionuclides in particulate form in surface waters in the exclusion zone around the Chernobyl Nuclear Power Plant. J. Contam.Hydrol. 35, 101-113 (1998).

109. Barnett, C. L. et al. Quantification of Radionuclide Transfer in Terrestrial and Freshwater Environments for Radiological Assessments. IAEA-TECDOC-1616. vol. No.1616 (IAEA, 2009).

110. Beresford, N. A. et al. Radionuclide transfer to wildlife at a 'Reference Site' in the Chernobyl Exclusion Zone and resultant radiation exposures. J. Environ. Radioact. 211, $105661(2020)$.

111. Beaugelin-Seiller, K., Jasserand, F., Garnier-Laplace, J. \& Gariel, J. C. Modeling radiological dose in non-human species: principles, computerization, and application. Health Phys. 90, 485-493 (2006).

112. Beresford, N. A. et al. Estimating the exposure of small mammals at three sites within the Chernobyl exclusion zone - a test application of the ERICA Tool. J. Environ. Radioact. 99, 1496-1502 (2008).

113. Stöck, M. et al. Mitochondrial and nuclear phylogeny of circum-Mediterranean tree frogs from the Hyla arborea group. Mol. Phylogenet. Evol. 49, 1019-1024 (2008).

114. Kumar, S., Stecher, G. \& Tamura, K. MEGA7: Molecular Evolutionary Genetics Analysis version 7.0 for bigger datasets. Mol. Biol. Evol. 33, 1870-1874 (2016). 
115. Hauswirth, W. W. \& Laipis, P. J. Mitochondrial DNA polymorphism in a maternal lineage of Holstein cows. PNAS 79, 4686-4690 (1982).

116. Kalinowski, S. T. hp-rare 1.0: a computer program for performing rarefaction on measures of allelic richness. Mol. Ecol. Notes 5, 187-189 (2005).

117. Nei, M. Molecular Evolutionary Genetics. (Columbia University Press, 1987).

118. Tajima, F. Evolutionary relationship of dna sequences in finite populations. Genetics 105, 437-460 (1983).

119. Ewens, W. J. The sampling theory of selectively neutral alleles. Theor. Popul. Biol. 3, 87-112 (1972).

120. Watterson, G. A. On the number of segregating sites in genetical models without recombination. Theor. Popul. Biol. 7, 256-276 (1975).

121. Excoffier, L., Laval, G. \& Schneider, S. Arlequin (version 3.0): An integrated software package for population genetics data analysis. Evol. Bioinform. Online 1, 47-50 (2005).

122. Belkhir, K., Borsa, P., Chikhi, L., Raufaste, N. \& Bonhomme, F. GENETIX 4.05, logiciel sous Windows TM pour la genetique des populations. (2004).

123. Szpiech, Z. A., Jakobsson, M. \& Rosenberg, N. A. ADZE: A rarefaction approach for counting alleles private to combinations of populations. Bioinformatics 24, 2498-2504 (2008).

124. Goudet, J. FSTAT (Version 1.2): A computer program to calculate F-statistics. $J$. Hered. 86, 485-486 (1995).

125. Rozas, J. et al. DnaSP 6: DNA sequence polymorphism analysis of large data sets. Mol. Biol. Evol. 34, 3299-3302 (2017).

126. Bandelt, H. J., Forster, P. \& Röhl, A. Median-joining networks for inferring intraspecific phylogenies. Mol. Biol. Evol. 16, 37-48 (1999). 
127. Leigh, J. W. \& Bryant, D. Popart: full-feature software for haplotype network construction. Methods Ecol. Evol. 6, 1110-1116 (2015).

128. Beaumont, M. A., Zhang, W. \& Balding, D. J. Approximate Bayesian computation in population genetics. Genetics 162, 2025-2035 (2002).

129. Paradis, E. Pegas: an R package for population genetics with an integrated-modular approach. Bioinformatics 26, 419-420 (2010).

130. Prost, S. \& Anderson, C. N. K. TempNet: a method to display statistical parsimony networks for heterochronous DNA sequence data. Methods Ecol. Evol. 2, 663-667 (2011).

131. Oksanen, J. et al. vegan: Community Ecology Package. (2009).

132. R Core Development Team. $R$ : A language and environment for statistical computing. (2009).

133. Tajima, F. Statistical method for testing the neutral mutation hypothesis by DNA polymorphism. Genetics 123, 585-595 (1989).

134. Fu, Y. X. \& Li, W. H. Statistical tests of neutrality of mutations. Genetics 133, 693709 (1993).

135. Ramos-Onsins, S. E. \& Rozas, J. Statistical properties of new neutrality tests against population growth. Mol. Biol. Evol. 19, 2092-2100 (2002). 
bioRxiv preprint doi: https://doi org/10.1101/202012 04 412114; this version posted December 6,2020 . The copyright holder for this

preprint (which was not certified by peer review) is the author/funder, who has granted bioRxiv a license to display the preprint in perpetuity. It is made available under aCC-BY-NC-ND 4.0 International license.

859

860

861

862

863

864

865

866

867

868

869

870

871

872

873

874

\section{Acknowledgments}

We are thankful to Jean-Michel Metivier (IRSN) for his help with GIS, to Yevgenii

Gulyaichenko (Chernobyl Center, Slavutych, Ukraine) for his help in the field, to Andrii

Maksymenko (Chernobyl Center, Slavutych, Ukraine) for the radionuclide assay of the samples, and to Julia Maklyuk and other staff of the Chernobyl Center (Slavutych, Ukraine)

for the generic arrangement and logistic during the field work in Chernobyl. Field work in the

Chernobyl Exclusion Zone was funded by EC EURATOM-60497 COMET project, Swedish

Radiation Protection Agency-SSM (SSM2017-269 and SSM2018-2038) and Carl Tryggers

Foundation (CT 16:344). Molecular analyses were funded by IRSN and the French NEEDS-

Environnement grant. Radiation analyses were funded by Swedish Radiation Protection

Agency-SSM (SSM2017-269 and SSM2018-2038). C. Car beneficed of an IRSN doctoral

fellowship. P. Burraco was supported by a Carl Tryggers Foundation project CT 16:344 and

by a Marie-Skłodowska-Curie individual fellowship (797879-METAGE project). G. Orizaola

was supported by the Spanish Ministry of Science, Innovation and Universities “Ramón y

Cajal” grant RYC-2016-20656. 


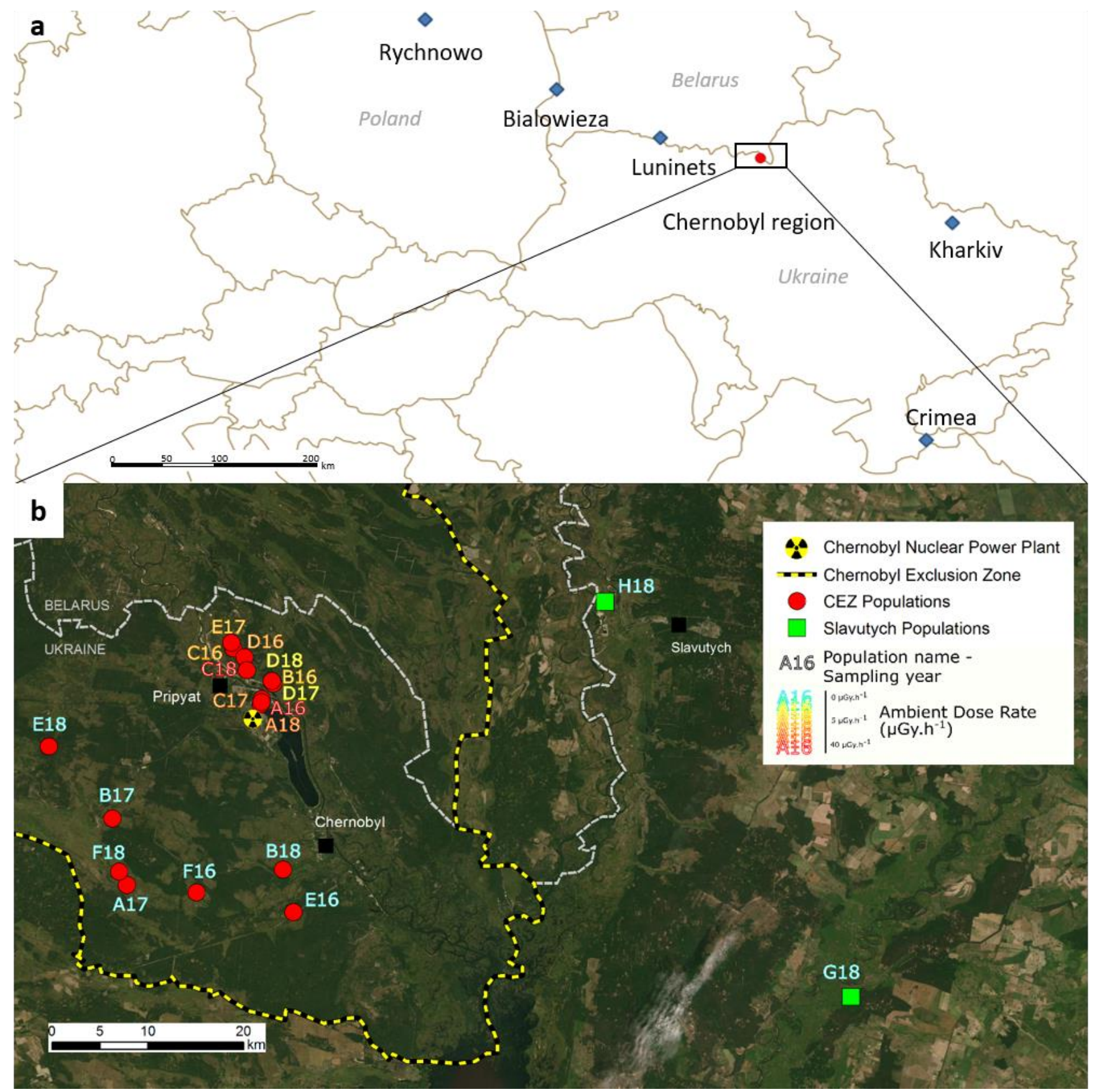

876 Figure 1: a. Location of European populations of Eastern tree frogs outside the Chernobyl

877 region sampled by Dufresnes et al. ${ }^{62}$ (blue diamonds) and the 19 populations sampled at the

878 Chernobyl region (red circles). b. Map of the Chernobyl region and location of the 19

879 populations sampled in 2016, 2017, 2018 in the CEZ and at Slavutych. The map was created

880 with ArcGis v. 10.5. Source and service layer credits for satellite imagery: Esri, DigitalGlobe,

881 GeoEye, Earthstar Geographics, CNES/Airbus DS, USDA, USGS, AeroGRID, IGN, and the

882 GIS User Community. 

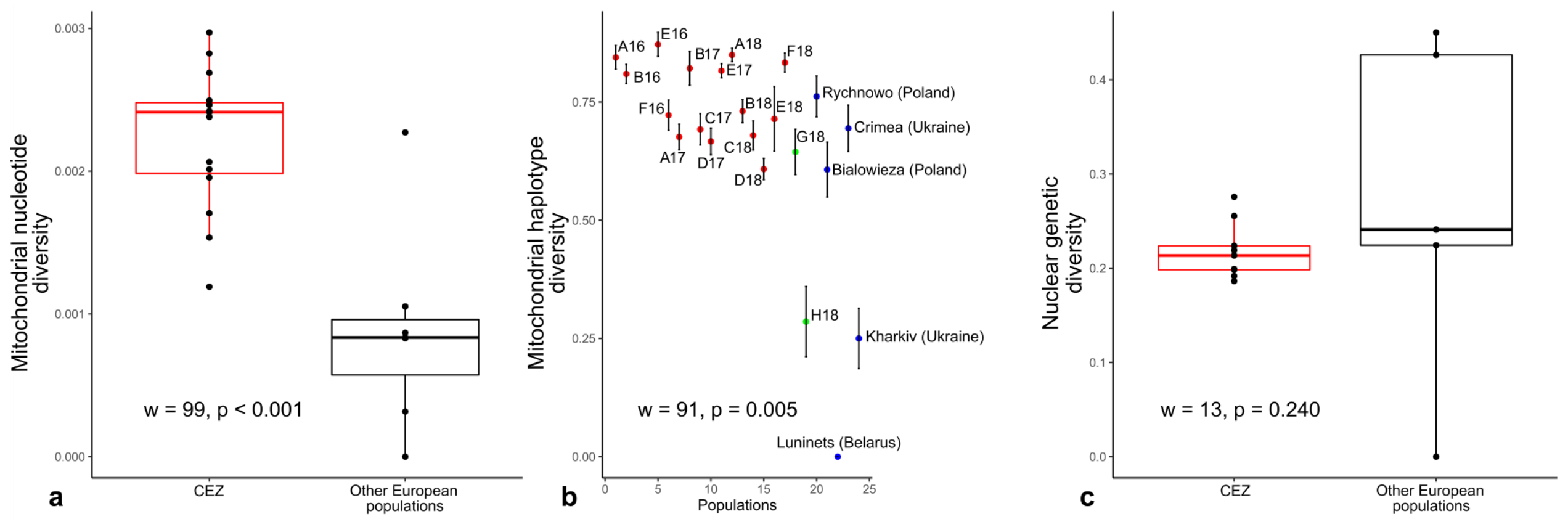

Figure 2: Comparison between genetic diversity estimates at the European level. a. Boxplot of mitochondrial nucleotide diversity (i.e. the probability that two randomly chosen nucleotides of the cytochrome $b$ at a homolog position are different ${ }^{117,118}$ ) for CEZ (red) and other European populations (black). Genetic diversity is higher at the CEZ than at other European populations (Mann-Whitney, w $=99, \mathrm{p}=0.0004)$. b. Mitochondrial haplotype diversity estimates (i.e. the probability that two randomly chosen haplotypes of the cytochrome $b$ are different ${ }^{117}$ ) \pm standard error for CEZ (red), populations from Slavutych (green) and sampled by Dufresnes et al. (blue) ${ }^{62}$. Genetic diversity is higher at the CEZ than at other European populations (Mann-Whitney, $w=91, p=0.005$ ). c. Boxplot of nuclear genetic diversity estimated on the 21 microsatellites markers ${ }^{117}$ for CEZ (red) and other European populations (blue). There are no significant differences between the genetic diversity of CEZ and other European populations (Mann-Whitney, w = 13, p = 0.240). 

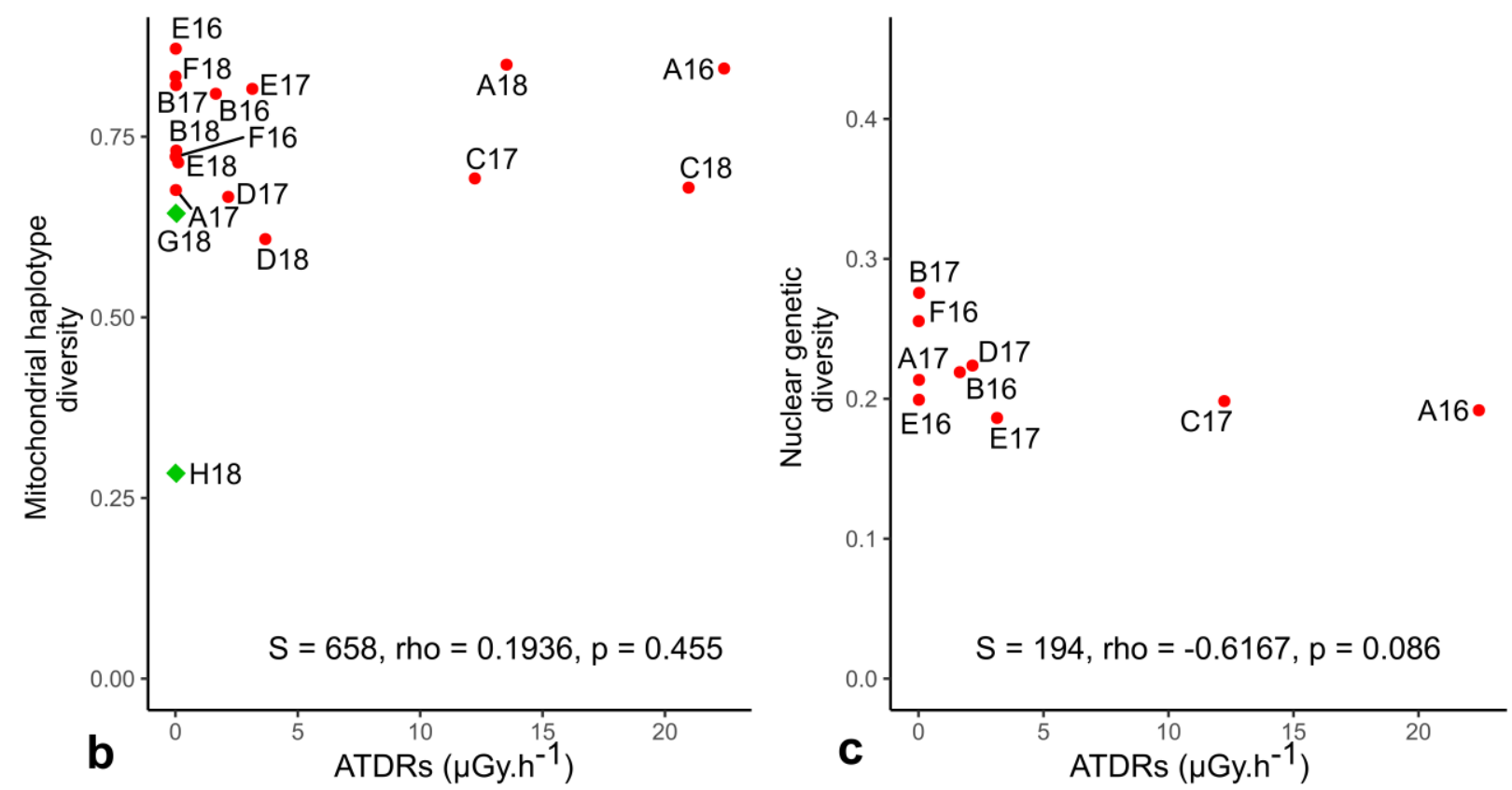

Figure 3: Correlation plots representing genetic diversity estimates on population-averaged dose rate (ATDR) in $\mu$ Gy.h ${ }^{-1}$. Only populations of the Chernobyl region (i.e. CEZ (red dots) and Slavutych (green diamonds), Fig. 1b) with sample size > 7 individuals were compared. a.

5 Mitochondrial nucleotide diversity estimates (i.e. the probability that two randomly chosen nucleotides of the cytochrome $b$ at a homolog 6 position are different ${ }^{117,118}$ ) on ambient dose rate of the corresponding population. Nucleotide diversity is positively correlated to ATDR ( $\mathrm{S}=$ 7294 , rho $=0.6397, \mathrm{p}=0.007$ ). b. Mitochondrial haplotype diversity estimates (i.e. the probability that two randomly chosen haplotypes of the 8 cytochrome $\mathrm{b}$ are different ${ }^{117}$ ) on ATDR of the corresponding population. Haplotype diversity is not correlated to ATDR ( $\mathrm{S}=, 658$ rho $=0.1936$, $9 \mathrm{p}=0.455)$. c. Nuclear genetic diversity $(\mathrm{Hs})$ estimated on the 21 microsatellites markers ${ }^{117}$ on ATDR. Genetic diversity is not correlated to ambient dose rate $(S=194$, rho $=-0.6167, \mathrm{p}=0.086)$. 

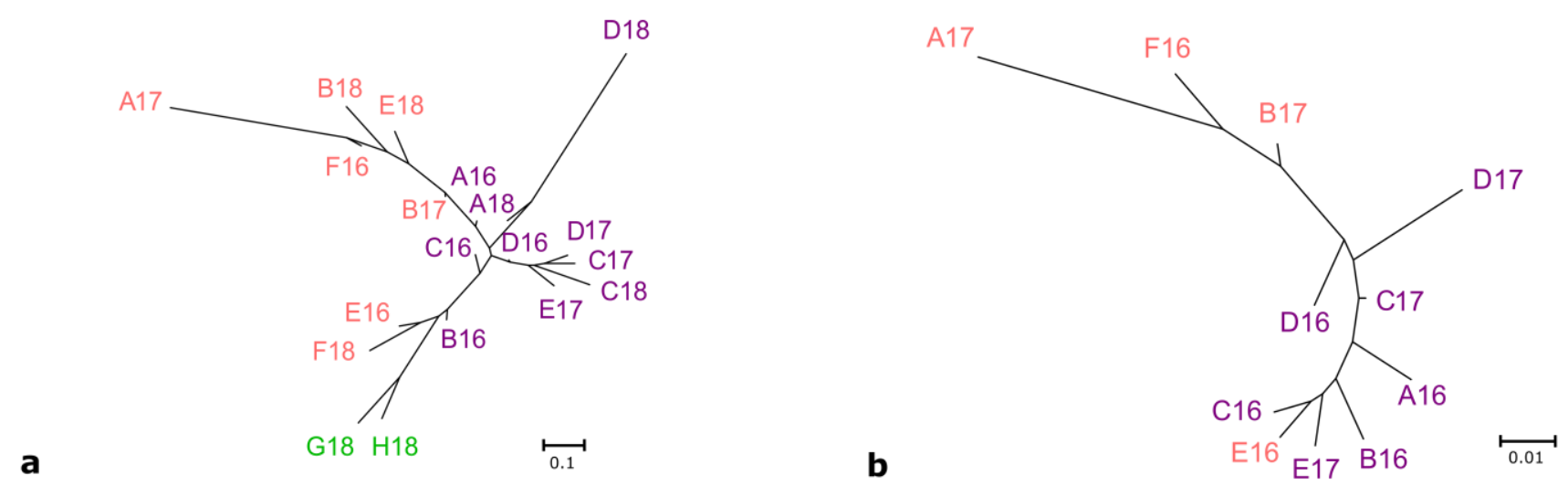

\begin{tabular}{lllllllll} 
& \multicolumn{9}{l}{ Years } & \multicolumn{5}{c}{ Geography } \\
Source of variation & d.f. & Sum of squares & Variance components & Variation (\%) & d.f. & Sum of squares & Variance components & Variation (\%) \\
Among groups & 2 & 10.111 & 0.02459 & $2.00($ N.S.) & 2 & 23.288 & 0.15786 & $12.27(* * *)$ \\
Among populations within groups & 16 & 48.707 & 0.17502 & $14.26(* * *)$ & 16 & 35.530 & 0.10145 & $7.88(* * *)$ \\
Within populations & 204 & 209.577 & 1.02734 & $83.73(* * *)$ & 204 & 209.577 & 1.02734 & $79.85(* * *)$ \\
\hline Total & 222 & 268.395 & 1.22695 & & 222 & 268.395 & 1.28665
\end{tabular}
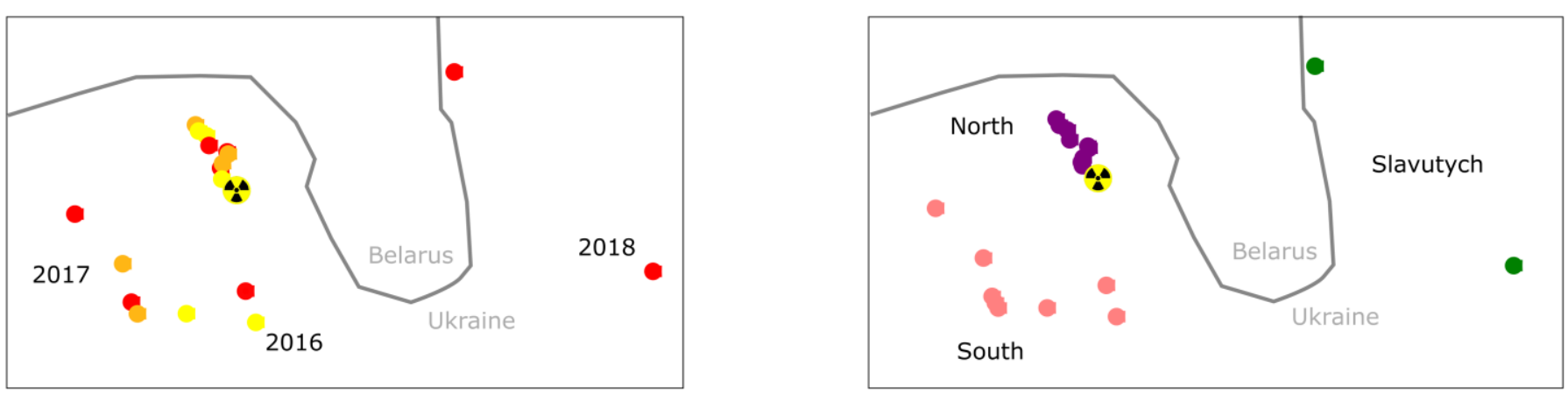

C

$3 \quad$ Figure 4: Genetic structure of the 19 populations of Eastern tree frogs from CEZ and

4 Slavutych. Neighbor-joining tree were constructed from genetic distances calculated as

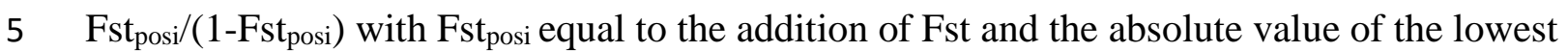

6 Fst in order to avoid negative values and respect proportionality of pairwise Fst (see Methods

7 for details). a. Neighbor Joining tree of CEZ (purple and pink) and Slavutych (green)

8 populations from cytochrome b (mtDNA). b. Neighbor-Joining tree of CEZ populations (red)

9 from microsatellites (nDNA). c. AMOVA analysis conducted on Year and Geographical

10 groups on mtDNA. Stars represent significance calculated from Arlequin with 1023

11 permutations $^{121}$ (***: sign < 0.001). Year groups are 2016, 2017, 2018 (2016: yellow, 2017: orange, 2018: red) and geographical groups are north close to the Chernobyl Nuclear Power Plant (radiation warning symbol), south distant form the north and Slavutych (north: purple, south: pink, Slavutych: green). 
Figure 5: Haplotype network constructed for Eastern tree frog cytochrome b sequences from CEZ (red), Slavutych (green) populations, and European populations sampled by Dufresnes et al. ${ }^{62}$ (blue) using the Median-Joining method ${ }^{126}$ and POPART software ${ }^{127}$. Circles representing haplotypes, their diameter is proportional to the number of individuals and the number of horizontal bars between haplotypes representing the number of nucleotides differing between haplotypes. The network structure can inform on the demographic status of populations: when the central haplotype is large compared to the surrounding haplotypes and lot of one step rare haplotypes surround this central haplotype (e.g. Slavutych and European populations), the population is in demographic expansion; if the central haplotype is not mainly represented and if there are a lot of two or three steps large haplotypes, the population is at the equilibrium mutation/drift and is often formerly diversified (CEZ populations). 

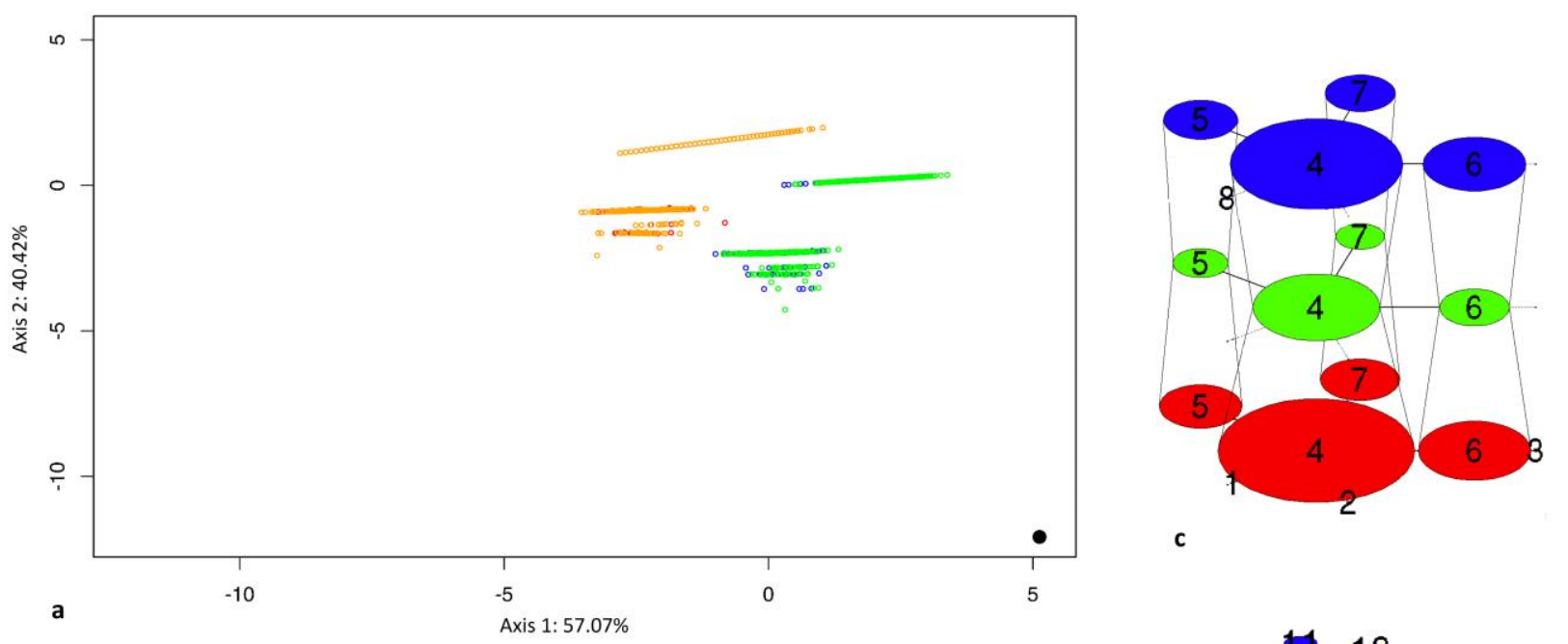

15 generations

10 generations

Prior

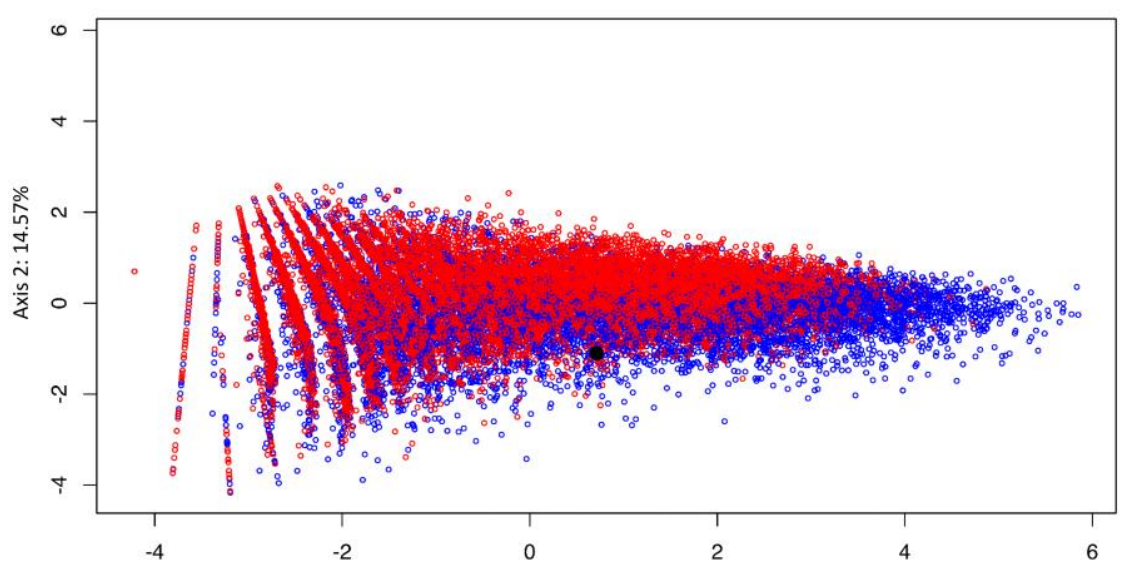

Axis 1: $77.59 \%$

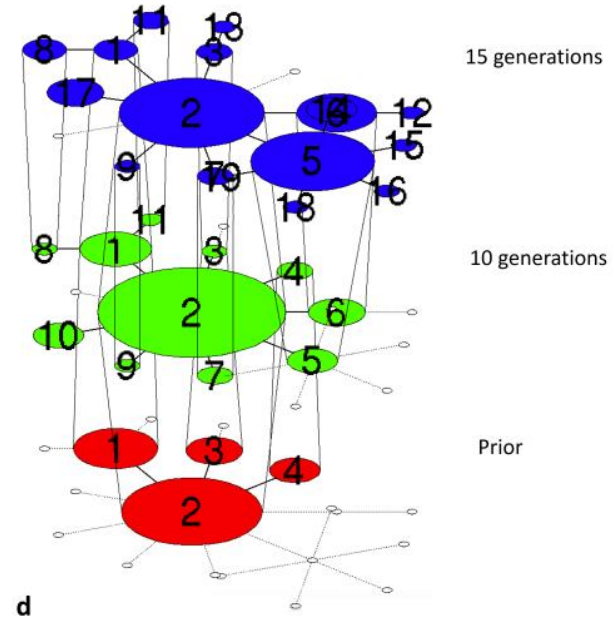

Figure 6: Mitochondrial haplotype network simulation. a. Representation of observed (black circle) and simulated (coloured open circles) data with a classical amphibian mitochondrial nucleotide substitution rate $\left(20.37 \times 10^{-9}\right.$ per nucleotide per generation), a population size sampled in a uniform distribution U(1000-5000), and starting from the H18 (orange) or G18 (green) population haplotype frequencies on the two first axis of a PCA made on a set of haplotype network statistics. The observed data is not in the space of the simulated data. $\mathbf{b}$. Representation of observed (black circle) and simulated (coloured circles) data with a high mitochondrial nucleotide substitution rate $(0.005,0.01,0.02,0.04,0.06,0.08)$ and small population size (sampled in a uniform distribution $\mathrm{U}(50,100), \mathrm{U}(100,200)$, or $\mathrm{U}(200,300)$ ) for 10 (red) and 15 (blue) generations on the two first axis of a PCA made on a set of haplotype network statistics. The observed data is in the space of the simulated data. c. One example of haplotype network evolutionary scenario of a simulated population starting from G18 population haplotype frequencies as prior with a classical amphibian substitution rate and populations sizes in the range of uniform distribution U(1000-5000) d. One example of haplotype network evolutionary scenario of a simulated population starting from G18 population haplotype frequencies as prior with a high substitution rate $(0.04)$ and a maximal effective size of 100 (for prior (red) and 10 (green) and 15 (blue) generations after the Chernobyl nuclear power plant accident). 